seven countries have more forested land. In the far north is cool-temperate forest, part of the vast north Eurasian coniferous belt. At the other extreme there are in the south tropical monsoon and rain forests. These forests are comparatively small - only three per cent of the country being in the tropics at all and only limited parts of that still forested. Nevertheless this zone has, like rain forests in other parts of the world, a great diversity of vegetation-there being well over 7000 species of higher plants including many endemics. Between these extremes are temperate coniferous and deciduous broadleaved mixed forest, warm-temperate deciduous broad-leaved forest, subtropical evergreen broad-leaved forest, and finally north-western mountain forests of mainly spruce and fir, which are in the north-western arid zone but where there is, nevertheless, sufficient rainfall in places to support trees. It is interesting to learn that China has 30 genera and some 300 species of bamboo, widely distributed over much of the country, though mainly of course in the tropical and subtropical parts.

Following the description of the forests the animals occurring in them are noted. If asked, most people would probably be able to name the giant panda among the mammals of China, but how much farther would they get? No fewer than 11 primates are mentioned-the slow loris, two macaques, five langurs (though two may be no more than subspecies) and three gibbons. To these may be added the Assamese macaque, which occurs in a limited part of south western Yunnan near the Burmese border, and the Taiwan macaque, both listed in the Appendices. Carnivora include brown and black bears, wild dog, tiger, leopard, clouded leopard, three smaller cats and some civets. The book is intended for the general reader and many mammals are omitted (though listed in the Appendices). I would have thought that such a well known species as the wolf would merit mention. There are several species of deer, gaur, and elephant, formerly fairly widespread in the south and surviving in limited numbers in the Xishuangbanna area of extreme southern Yunnan. The section on birds is somewhat longer than that on mammals and largely taken up by the Phasianidae of which China has 49 species, ranging from the temperate zone capercaillie and black grouse to the tropical grey peacock-pheasant and green peafowl. The chapter concludes with a very brief paragraph on reptiles, amphibians and insects. Similar chapters follow on Rivers, Lakes and Sea coasts, Mountains, Grasslands, and Deserts.

In the final chapter,

Conservation and Nature Protection, it is not surprising to learn that the familiar spectres of soil erosion, water loss, land degradation and desertification, deforestation and pollution are also problems in China What will pleasantly surprise many readers is the extent to which this has apparently been recognized (albeit, as so often elsewhere, much later than it should have been) and corrective measures instituted. Current land management, largely aimed at safeguarding productivity of agricultural land, planting (or re-planting) forests, and protection from pollution (including for example treating coal to remove sulphur before it is burnt) are mentioned. The remainder of the chapter deals with nature conservation per se including protection of rare species, nature reserves, and captivebreeding programmes. Three maps show the location of 219 nature reserves in the southeast, west and north-east. Short accounts are given of a few reserves, including

Xishuangbanna, $2000 \mathrm{~km}$, which in addition to the elephant has more than 4000 angiosperm species including 50 per cent of China's legally protected plants. One can only hope that the stated conservation measures are being implemented in practice. Appendices list, with scientific as well as English names, typical mammals, birds, and reptiles of the major natural regions.

The numerous colour photographs, reproduced to a uniformly high standard, are the most impressive feature of this beautifully produced book. Most of the birds and mammals depicted appear to be genuinely wild-only a few are obviously captive. The pictures taken by Zhang Cizu of several cats, a young takin and a red goral are particularly good. I cannot understand why it was thought necessary to split the photos of the clouded leopard and tiger between two pages.

The book gives an interesting insight into the habitats, fauna flora of China hitherto unknown to the vast majority of people outside the country. V.F.H. Ansell.

\section{Animal Reintroductions: The Arabian Oryx in Oman Mark R. Stanley Price Cambridge University Press, 1989, 291pp., HB $£ 17.50$}

It is a sad fact of the modern world that more and more animals and plants are on their way to extinction, and most of them are only likely to be saved 
by reintroduction. Using the Arabian oryx Oryx leucoryx as his exemplar, Mark Stanley Price here examines, scientifically, the problems of reintroducing animals into the wild. His qualification for so doing is unequalled, for he himself directed the first known project whereby an animal that had become extinct in the wild was successfully reintroduced there as a self-sustaining breeding stock. He warns, however, that the 20 years that elapsed between 1972, when the Arabian oryx was exterminated in the wild and its successful return to the Jiddat-al-Harasis in central Oman, may prove to have been misleadingly short. Future attempts may well take much longer.

The Oman project was first conceived only two years after the extinction. It was proposed by the Ruler of Oman, $\mathrm{H} \mathrm{M}$ Sultan Qaboos bin Said, planned with military precision by his conservation advisor, Col Ralph Daly, and carried out with scrupulous scientific care and attention to detail by Dr Stanley Price, who had been researching the domesticated beisa oryx of the Galana Game Ranch Research Project in Kenya. In this book he describes meticulously the immense and time-consuming undertaking that led to the project's success. It was scientifically planned all the way. $\mathrm{He}$ also gives an extremely valuable scientific assessment of the problems facing those who seek to repeat this success with other species. Indeed, it would be irresponsible to commit any substantial conservation resources to the reintroduction of any land vertebrate without taking into account the scientific considerations advanced here.

For it is clear that a large element of uncovenanted good fortune attended the success of the project. Dr Stanley Price believes that FPS's Operation Oryx, which made the whole enterprise possible, was carried out in the last year in which it had a reasonable chance of success-at one point it was nearly postponed when one of its main backers withdrew. It is clear too that without the foresight and determination of an enlightened Ruler, this very complex project, involving prolonged negotiations with local tribesmen, foreign zoos, international scientists and conservationists, and many others, would never have got off the ground. Morever, Dr Stanley Price believes it was a mistake to dissolve the World Herd Trustees so soon. Their continued existence would certainly have solved some of the problems the Oman Government had to face. And behind this lies another mistake: IUCN and WWF International should both have been initial trustees.

Nevertheless the Sultan and his men brought off a great triumph, a triumph in which the FPS had played a key part, not only by sponsoring Operation Oryx, but also in sticking to it when a more faint-hearted society might have faltered. Richard Fitter.

\section{Lemurs of Madagascar and the Comoros: The IUCN Red Data Book}

C. Harcourt and J. Thornback IUCN, Gland and Cambridge, 1990, 248 pp, £18/\$US36 plus postage (add $15 \%$ for UK, $17.5 \%$ for overseas surface and $40 \%$ for airmail), available from IUCN Publications Service Unit, $219 \mathrm{c}$

Huntingdon Road, Cambridge CB3 ODL, UK.

This latest volume in the IUCN Red Data Book series provides the most up-to-date and comprehensive review available on the conservation status of lemurs. A detailed account is provided for all Madagascar's species, giving information on distribution, population status, habitat, ecology, threats, conservation action, captive breeding and a bibliography. There are black and white photographs of nearly all species and distribution maps.

Editor.

\section{International Zoo Yearbook 28}

Edited by P. J. S. Olney and Pat Ellis

Zoological Society of London, 1989,557 pp.,HB $€ 48.50$, \$US 82.45, SB $€ 43.00$, \$US 73.10

A substantial part of volume 28 of the International Zoo Yearbook deals with the latest work on reptiles and amphibians in zoos and zoological institutions. It comprises 40 papers from the world's leading herpetologists dealing with a diverse range of topics, and species, from reproduction and behaviour to the management of captive populations, conservation problems and reintroduction into the wild.

Section 2 consists of 14 papers on the management and breeding of birds and mammals in collections and Section 3 comprises the annual worldwide census of animals bred in zoos, the census of rare animals held in zoos and an up-to-date list of all International Studbooks. There is also a $97-$ page directory of zoos and aquaria around the world.

This excellent publication, well illustrated with photographs and diagrams, is an invaluable reference work for anyone interested in zoology or conservation.

Editor. 